\title{
GROWTH, STRUCTURAL AND OPTICAL STUDIES ON PURE AND L-HISTIDINE DOPED SINGLE CRYSTALS OF COPPER SULPHATE
}

\author{
M.Mary Anne', S.Perumal' ${ }^{2}$, K.Monikanda Prabu ${ }^{3}$ \\ ${ }^{1}$ Assistant Lecturer, Department of Physics, DMI, St. Eugene University, Lusaka, Zambia, Central Africa \\ ${ }^{2}$ Principal, South Travancore Hindu College, Nagercoil-2, Tamilnadu, India \\ ${ }^{3}$ Research Scholar, Physics Research Centre, South Travancore Hindu College, Nagercoil-2, Tamilnadu, India
}

\begin{abstract}
Single crystals of pure and L-Histidine doped copper sulphate penta hydrate $\left(\mathrm{CuSO}_{4} .5 \mathrm{H}_{2} \mathrm{O}\right)$ were grown by slow evaporation method at room temperature. The grown crystals were carried out by Powder X-ray diffraction analysis to find out the crystalline nature. The different modes of vibration present in the pure and L-Histidine doped $\mathrm{CuSO}_{4}$ crystals were identified by FITR spectra. The wide optical transparency in the entire visible region was shown by UV-Vis-spectral analysis.
\end{abstract}

Keywords: Crystal Growth, XRD, FTIR, UV-Visible

\section{INTRODUCTION}

The anhydrous form of copper sulphate is a pale green or gray-white powder. However, its pentahydrate $\left(\mathrm{CuSO}_{4} \cdot 5 \mathrm{H}_{2} \mathrm{O}\right)$ form is bright blue in colour. Copper sulphate exothermically dissolves in water to give the aquo complex $\left[\mathrm{Cu}\left(\mathrm{H}_{2} \mathrm{O}\right)_{6}\right]^{2+}$, which has octahedral molecular geometry and is paramagnetic. Other names for copper sulphates are copper (II) sulphate, "blue vitriol" and "bluestone". Crystal's exhibit non-linear optical (NLO) property has been of great importance in recent years because of their wide spread applications such as high-speed information processing, optical communications and optical data storage, photonics and electro optics modulation $[1,2]$. These crystals are useful for nonlinear optical devices based on their optical second harmonic generation. The NLO property of glycine added copper sulphate single crystal was reported by S.N. Jeyanthi etal. very recently [3]. Copper sulphate also applicable in synthetic fibre industry, used as an electrolyte in copper refining, the paint industry uses it in anti-fouling paints and it plays a part in the coloring of glass, antiseptic agent, and antifungal agent. The goal of this paper is to give report about the growth of pure and L-Histidine doped copper sulphate single crystals by slow evaporation method, the structural and optical properties of the grown crystals were identified by powder X-ray diffraction data, Fourier Transform Infrared and UVVis spectral analysis.

\section{EXPERIMENTAL}

\subsection{Crystal Growth}

Analytical Reagent (AR) grade copper sulphate salt was used for the growth of pure and L-Histidine doped copper sulphate single crystals. Accordance with the solubility test suitable amount of copper sulphate salt was weighted. The mixture of deionised water and copper sulphate salt placed in a magnetic stirrer and is stir well with applying mild temperature about $40^{\circ} \mathrm{C}$. The stirring was continued until a homogeneous saturated solution was obtained. For doping purpose $0.002 \mathrm{wt} \%$ L-Histidine was added to the same solution. Then the solution was optimally covered using a plane thin paper sheet. Good quality transparent crystals were grown within 10-15 days. The grown crystals were carried out powder X-ray diffraction, Fourier Transform Infrared and UV-Visible spectral analysis.Transparent good quality crystals with perfect shape and free from macro defects were used for characterization.

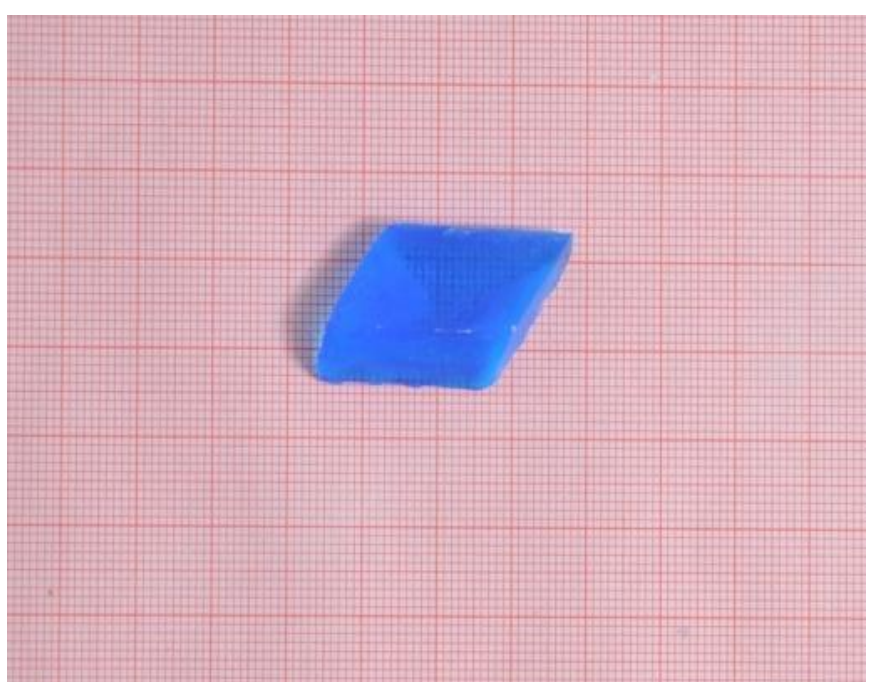

Fig -1: Photograph of pure copper sulphate single crystal 


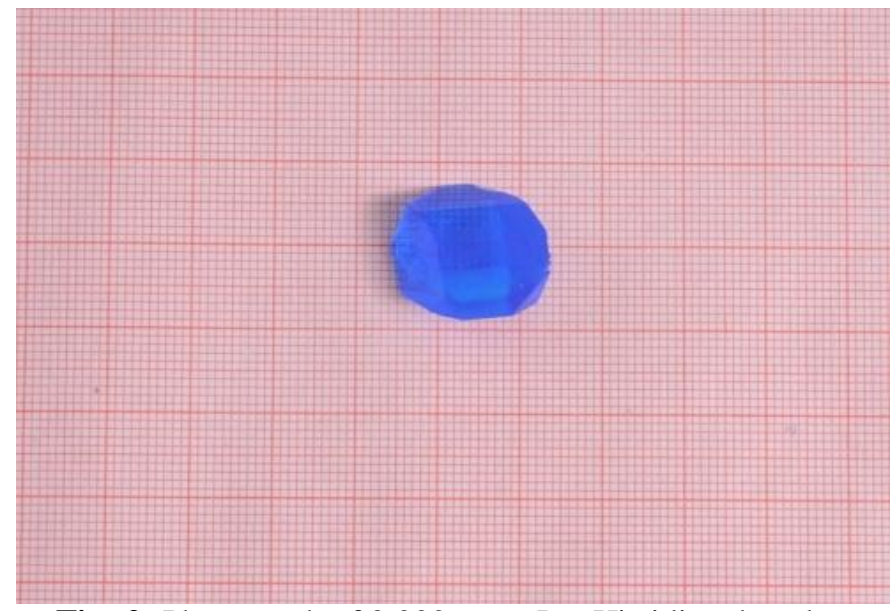

Fig -2: Photograph of 0.002 wt \% L - Histidine doped copper sulphate single crystal

\subsection{Material Characterization}

The grown pure and L - Histidine doped copper sulphate single crystal were characterized by Powder X-ray diffraction using XPERTPRO diffractometer. FTIR spectra of the grown crystals were characterized by Jasco 4100 Spectrophotometer equipped with ATR. UV-Vis absorption spectra of the grown crystals were recorded using Systronics $\mathrm{UV}-\mathrm{Vis}$ double beam spectrophotometer.

\section{RESULTS AND DISCUSSION}

\subsection{Powder X-ray Diffraction Analysis}

The powdered forms of the grown crystals were subjected to powder X-ray diffraction analysis. The X-ray diffraction data were recorded using monochromatic $\mathrm{CuK} \alpha-1$ radiation of wavelength $1.54060 \AA$ recorded between $2 \theta$ ranging from $10^{\circ}$ to $80^{\circ}$. The diffraction pattern contains various reflections corresponding to various crystallographic planes. The narrow peaks in the XRD pattern show the good quality crystalline nature of the grown crystals [4, 5]. The data obtained is good agreement with standard JCPDS file (JCPDS 77-1900) of copper sulphate pentahydrate single crystal. The reflection planes were indexed accordance with the JCPDS file. The presence of the doping in the composition of copper sulphate crystal increases the intensity of peaks comparing to pure copper sulphate crystal. This reveals that the doping has brought a change in the internal structure of the crystal [6]. From powder X-ray diffraction analysis, it has been confirmed that the grown pure and doped copper sulphate crystal belongs to triclinic system. The calculated lattice parameters show in table (1).

Table -1: Lattice parameters of pure and $0.002 \mathrm{wt} \% \mathrm{~L}$ Histidine doped copper sulphate single crystals

\begin{tabular}{|l|l|l|}
\hline system & $\begin{array}{l}\text { Pure copper } \\
\text { sulphate }\end{array}$ & $\begin{array}{l}0.002 \text { wt\% L- } \\
\text { Histidine doped } \\
\text { copper sulphate }\end{array}$ \\
\hline $\mathrm{a}\left(\mathrm{A}^{\circ}\right)$ & 6.121 & 6.101 \\
\hline $\mathrm{b}\left(\mathrm{A}^{\circ}\right)$ & 10.678 & 10.737 \\
\hline $\mathrm{c}\left(\mathrm{A}^{\circ}\right)$ & 5.931 & 5.987 \\
\hline$\alpha\left(^{\circ}\right)$ & 81.82 & 82.73 \\
\hline
\end{tabular}

\begin{tabular}{|l|l|l|}
\hline$\beta\left(^{\circ}\right)$ & 107.41 & 107.17 \\
\hline$\gamma\left({ }^{\circ}\right)$ & 102.41 & 102.72 \\
\hline Volume $\left(\mathrm{A}^{\circ}\right)^{3}$ & 360.056 & 364.766 \\
\hline
\end{tabular}

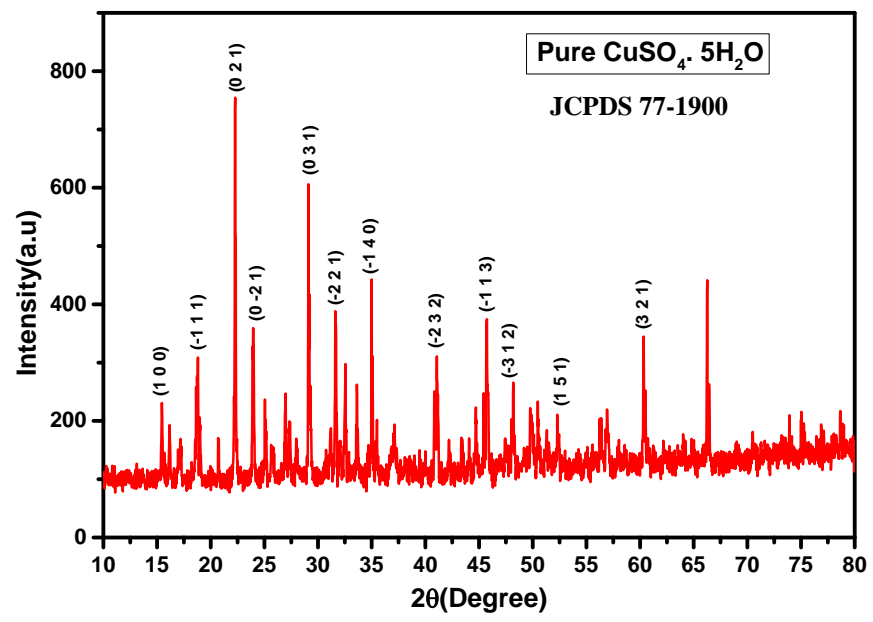

Fig -3: Powder X-ray diffraction pattern of pure copper sulphate single crystal

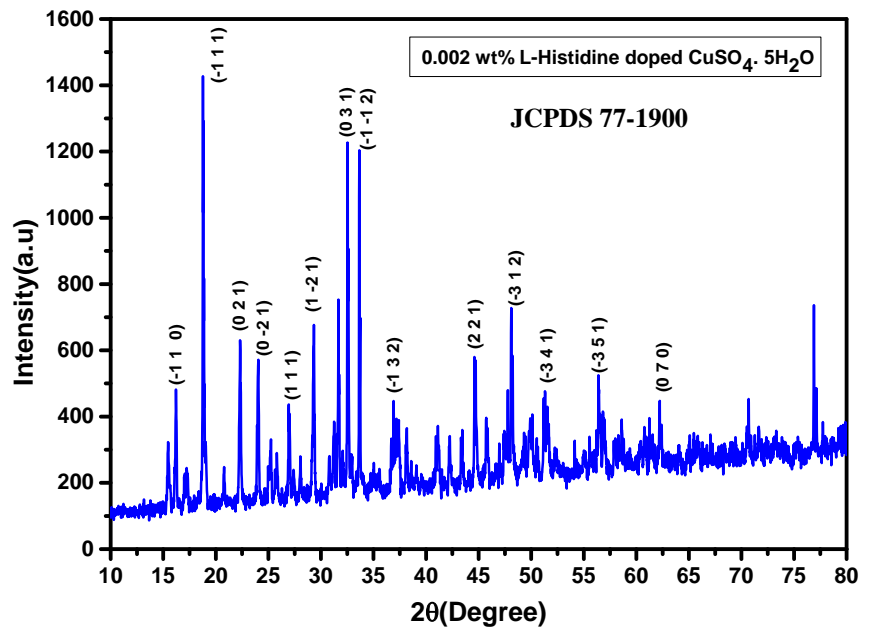

Fig -4: Powder X-ray diffraction pattern of 0.002 wt \%

$\mathrm{L}$ - Histidine doped copper sulphate single crystal

\subsection{Fourier Transform Infrared (FTIR) Analysis}

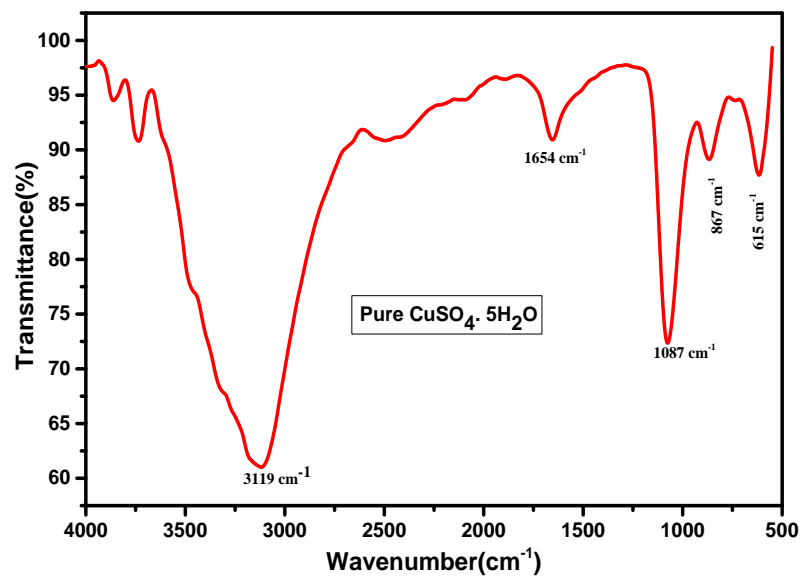

Fig -5: FTIR spectra of pure copper sulphate single crystal 
Fourier Transform Infrared spectral analysis is one of the most prominent and broadly used spectroscopic methods for analysing the structure of unknown compounds quantitatively. It is useful to find out the functional groups, internal structure of the molecules and the nature chemical bonds of a compound. The Fourier Transform Infrared spectra of pure and L-Histidine doped copper sulphate crystals were recorded in the range of $550-4000 \mathrm{~cm}^{-1}$. The FTIR spectra of pure and doped copper sulphate crystals were shown in figure (5) and figure (6) respectively.

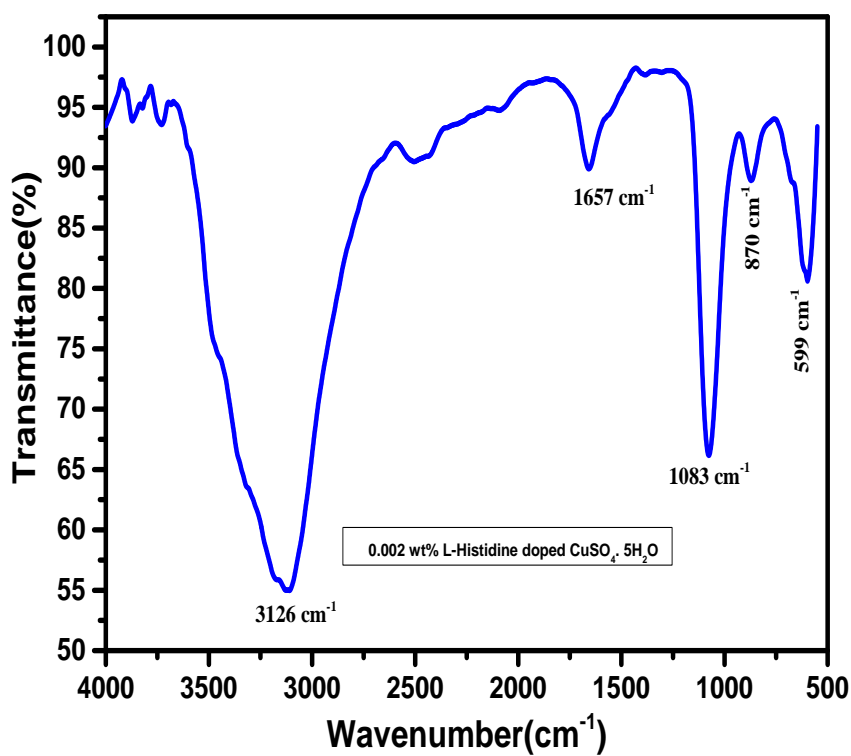

Fig -6: FTIR spectra of 0.002 wt \% L - Histidine doped copper sulphate single crystal

For pure copper sulphate single crystal the band at 3119 $\mathrm{cm}^{-1}$ assigned to stretching vibration of $\mathrm{O}-\mathrm{H}$ group [7]. The bending vibration mode of $\mathrm{O}-\mathrm{H}$ group identified at 1654 $\mathrm{cm}^{-1}$. The stretching vibration mode of S-O group found at $1087 \mathrm{~cm}^{-1}$. The bending vibration mode of S-O group were identified at $615 \mathrm{~cm}^{-1}$ [8]. The vibration mode of metal ion $\mathrm{Cu}^{2+}$ may be observed at $\mathrm{Cu}-\mathrm{O}-\mathrm{H}$ vibration and is assigned to $867 \mathrm{~cm}^{-1}$.

For L - Histidine doped copper sulphate single crystal the stretching and bending vibration mode of $\mathrm{O}-\mathrm{H}$ group shifted to $3126 \mathrm{~cm}^{-1}$ and $1657 \mathrm{~cm}^{-1}$ respectively. The shifting stretching and bending vibration mode of $\mathrm{S}-\mathrm{O}$ group observed at $1083 \mathrm{~cm}^{-1}$ and $599 \mathrm{~cm}^{-1}$. Similar observations were previously reported by F. A. Miller and C. H. Wilkins for AR grade copper sulphate salt [9].

\subsection{UV - Vis Spectral Analysis}

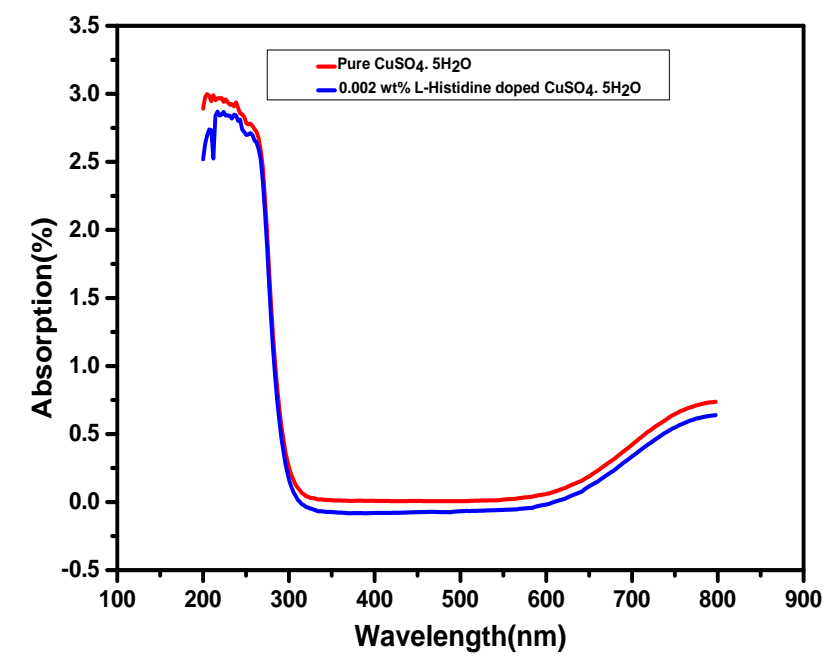

Fig -7: UV - Visible absorption spectra of pure and 0.002 $\mathrm{wt} \% \mathrm{~L}$-Histidine doped copper sulphate single crystal

UV-Visible absorption spectra of pure and the L - Histidine doped copper sulphate crystals were recorded by using Systronics double beam spectrophotometer-2201 in the wavelength range $200-800 \mathrm{~nm}$. The spectra were shown in figure (7).

From the UV-Visible absorption spectrum the absorbance is less than one unit in the entire visible region. The pure and L-Histidine doped copper sulphate crystals is very transparent in the wavelength range $320-600 \mathrm{~nm}$. This is the essential property for NLO materials [2]. The UV cut-off wavelength of pure and $\mathrm{L}$ - Histidine doped copper sulphate crystals were almost same and is lies near $304 \mathrm{~nm}$. The band gap value of copper sulphate crystal was found out using the relation $\mathrm{E}=\mathrm{h} v$ and is found to be $4.08 \mathrm{eV}$. Similar results were reported by S.M. Delphine and etal. [10].

\section{CONCLUSION}

Single crystals of pure and L-Histidine doped copper sulphate were grown by slow evaporation method. The powder X-ray diffraction analysis revealed that the crystal belongs to triclinic system. Small variations in the lattice parameters for the doped crystal have been noted. The vibrational modes of functional groups were identified using FTIR spectroscopic technique. The UV-Vis spectral study highlights the excellent transparency of the crystal in the entire visible region.

\section{ACKNOWLEDGEMENTS}

The authors acknowledge the Management of S.T.Hindu College for carry out the problem.

\section{REFERENCES}

[1]. K. Boopathi, P. Ramasamy, G. Bhagavannarayana, Growth and characterization of $\mathrm{Cu}$ (II) doped negatively soluble lithium sulphate monohydrate crystals, Journal of Crystal Growth, 386 (2014) 32-37. 
[2]. S. Ravi and S. Chenthamarai, Growth and Characterization of single crystals of Thiourea based Compounds, Indian Journal of Scientific Research, 9 (2014) 051-057.

[3]. S. N. Jayanthi , A.R. Prabhakaran, D. Subashini, K. Thamizharasan, Crystallization and Characterization of NLO active glycine copper sulphate crystal, Chalcogenide Letters, 11 (2014) 241-247.

[4]. M. Mahadevan , K. Ramachandran, Crystal growth, Structural, Thermal and Optical Properties of Potassium Para Nitrophenolate dihydrate Semi organic Single Crystal for NLO application, International Journal of Innovative Research in Science, Engineering and Technology, 3 (2014) 8785-8792.

[5]. J. Anitha Hudson, C.K. Mahadevan, C.M. Padma, Growth and Characterization of ADP Single Crystals Added With CdS, Int. Journal of Engineering Research and Applications, 4 (2014) 257-266.

[6]. T. Prasanyaa and M. Haris, Growth and characterization of semiorganic NLO L-arginine trifluoroacetate (LATF) added KDP single crystals, Archives of Physics Research, 2 (2011) 60-66.

[7]. M.R. Jagadeesh, H. M. Suresh Kumar, R. Ananda Kumari, Growth and characterization of an organic NLO crystal: L-alanine-2-furoic acid, Archives of Applied Science Research, 6 (2014) 188-197.

[8]. Briyan C. Smith, Infrared Spectral Interpretation-A systematic Approach, CRC Press (1999), New York.

[9]. F. A. Miller and C. H. Wilkins, Infrared Spectra and Characteristic Frequencies of Inorganic Ions, Analytical Chemistry, 24 (1952) 1253-1294.

[10]. S. Mary Delphine, R. Krishna Priya, T. Lidia Arockia Thai, S. Ajitha, Growth and characterization of L- histidine doped copper sulphate crystals, Archives of Applied Science Research, 6 (2014) 157-161.

\section{BIOGRAPHIES}

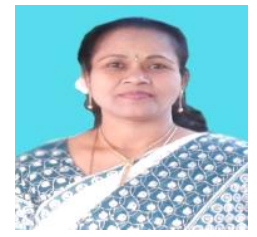

Ms. M.Mary Anne M.Sc., Assistant Lecturer, Department of Physics, DMI, St. Eugene University, Lusaka, Zambia, Central Africa.

Email: maryannie32@yahoo.com

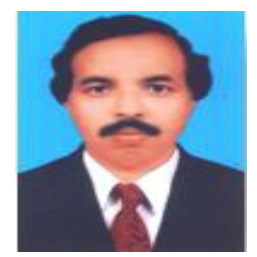

Dr.S.PERUMAL， M.Sc., M.Phil., Ph.D, Principal, S.T.Hindu College, Nagercoil-629002.

Email: spee58@gmail.com

Mobile: 9443119441

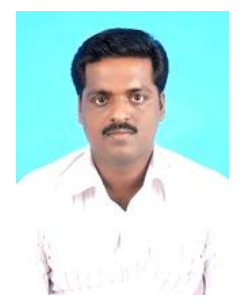

Mr.K.MONIKANDA PRABU, M.Sc., M.Phil., Research Scholar, Physics Research Centre , S.T.Hindu College, Nagercoil-629002.

Email: mkprabu1985@gmail.com

Mobile: 9095964636 